\title{
ESTADO LIBERAL E ENSINO SUPERIOR: 0 IMPACTO DAS DEMANDAS DO MERCADO SOBRE AS POLÍTICAS EDUCACIONAIS NA UNIVERSIDADE PÚBLICA
}

\section{État libéral et éducation supérieure: L'cImpact des Demandes du Marché sur la Politique éducative à l'cUniversité Publique}

Maria de Lourdes Pinto de Almeida ${ }^{1}$

\section{Resumo}

Estabeleceremos neste texto algumas correlações entre Estado, mercado e trabalho acadêmico. Para uma abordagem mais ampla dessa questão tomase necessánio caracterizar as diversas tendências do ideário liberal. Várias abordagens são possíveis a respeito do papel da universidade no sistema capitalista. Contudo, nos limitaremos a uma análise mais específica, abordando o tema sob a perspectiva da Economia Política em que prevalece a defesa do mercado como ideal de auto-organização ou coordenação das atividades econômicas. Posteriormente, indicaremos como a noção de rede tende a explicar o sistema liberal em vários níveis de seu funcionamento.

Palavras-chave:: História da Educação; Globalização e Educação; Capitalismo-Mercado-Educação; Liberalismo Econômico e Educação.

\section{Résumé}

Nous établirons dans ce texte quelques corrélations entre l'état, le marché et le travail scolaire. Pour une analyse plus ample de cette question on devient nécessaire caractériser les tendances diverses de l'ideánio libéral. Quelques abordages sont possibles concemant le papier de l'université dans le système capitaliste. Cependant, nous limiterons, dans ce texte, à une analyse plus

\footnotetext{
Pedagoga e Historiadora, Mestre e Doutora em História da Educação pela FE da UNICAMP. Docente do PPG em Educação da Universidade Tuiuti do Paraná. Membro da Sociedade Brasileira de História da Educação. Pesquisadora do Núcleo de Estudos e Pesquisas em Ensino Superior da FE da Unicamp, GEPES. Pós Doutoranda em Política Científica e Tecnológica. Coordenadora da Linha de Pesquisa Políticas Públicas e Gestão da Educação da UTP-Curitiba. Professora Pesquisadora da Sociedade Brasileira de História da Educação.
} 
spécifique, analysant le sujet sous la perspective de l'économie politique où le marché défendre l'idéale de l'auto-organisation ou de la coordination des activités économiques. Ensuite, nous indiquerons comme la notion réseau tend à expliquer le système libéral dans quelques niveaux de son fonctionnement.

Mot-clef: Histoire de l'éducation; Globalization et éducation; CapitalismeMarcché-Éducation; Libéralisme économique et éducation.

A retórica liberal tenta opor tendências de mercado como extremos irreconciliáveis: "Fundamentalmente só há dois meios de coordenar as atividades econômicas de milhões. Um deles é a direção central utilizando a coerção - a técnica do Exército e do Estado totalitário moderno. O outro é a cooperação voluntária dos indivíduos - a técnica do mercado".(FRIEDMAN, 1977, p. 21).

E, como enuncia também Ianni (1996, p.152), no mundo globalizado não só os Estados Nacionais continuam desenvolvendo planejamentos e estratégias, como também as empresas, em especial as grandes corporações, "0 princípio do mercado não elimina o princípio do planejamento. Ambos subsistem todo o tempo no âmbito do capitalismo, em seus níveis setoriais, nacionais, regionais e mundiais". Mesmo quando os governos reduzem sua interferência no jogo das forças produtivas, mesmo nesses casos subsistem diretrizes, estímulos, restrições e punições que orientam decisões e opções dos proprietários dos meios de produção; o que sempre envolve a institucionalização e o controle das condições sociais e jurídico-políticas da força de trabalho. Para evitar que o caos irrompa de modo avassalador, governantes, proprietários dos meios de produção, gerentes, técnicos, organizações multilaterais, ou seja, tecno-estruturas transnacionais ou propriamente mundiais planejam a expansão e a consolidação dos empreendimentos, a competição e a consolidação dos empreendimentos, o certo e o incerto.

No tocante ao liberalismo, este tem encontrado defesas radicais, no sentido de se fazer valer a 'maravilha do mercado'. Pode-se destacar, como fonte desse radicalismo, o princípio da redução máxima do papel do Estado. Os liberais surgiram em contraposição às doutrinas mercantilistas, que, mesmo admitindo a limitação das regulamentações internas, eram mais favoráveis a uma política governamental ativa, destinada a aumentar a participação da nacional nos mercados internacionais. Os liberais, a partir dos fisiocratas e de Adam Smith, radicalizaram o princípio da liberdade interna e ainda mais na esfera externa.

O credo liberal foi-se afirmando, graças a industrialização, frente aos princípios da ética paternalista católica e do mercantilismo. Nesse sentido, o individualismo inerente ao liberalismo clássico tornou-se a ideologia dominante do capitalismo, cujos princípios norteadores foram o egoísmo, a frieza 
calculista e o atomismo. Movidos pelos impulsos egoístas de maximizar sua felicidade, isto é, diminuir o sofrimento e aumentar os prazeres. A . Smith, o grande sistematizador do ideário liberal, afirma, por exemplo, que devemos esperar o pão não da bondade do padeiro, mas do seu egoísmo, pois seria pensando em aumentar os seus lucros e não em fazer uma boa ação que ele se empenharia em produzir suas mercadorias. Nesse sentido, o papel da razão é fundamental para se compreender a ação do indivíduo:

Embora todas as motivações tenham origem no prazer e na dor, as decisões que os indivíduos tomam quanto a que prazeres ou dores buscar ou evitar baseiam-se numa avaliação fria, desapaixonada, racional, das situações. É a razão quem dita a necessidade de avaliar todas as alternativas que determinada situação coloca para que a escolha recaia sobre a que oferece o máximo de prazer e o mínimo de dor. Aí está a vertente calculista e intelectual da teoria psicológica do liberalismo clássico: a ênfase que confere à avaliação racional dos prazeres e dores e, em contrapartida, o menosprezo pelo capricho, o instinto, o hábito, o costume e as convenções.

Ao lado do egoísmo calculista, destaca-se a atribuição de uma inércia originária constituindo a natureza humana. Nesse aspecto, os fatores desencadeadores da ação seriam o prazer e a dor. Como disse Bentham, a natureza submeteu o homem a dois senhores: a dor e o prazer. Sendo que o prazer difere apenas quanto à intensidade, sem, portanto, haver diferenças de qualidade entre ambos. As conseqüências práticas dessa doutrina, escrevem Hunt e Sherman (1977), seria o preconceito em relação aos trabalhadores, que eram vistos como incuravelmente preguiçosos. Os referidos autores citam o Reverendo Joseph Townsend, para quem a fome exerceria não só uma pressão mansa, silenciosa e incessante, sendo a motivação fundamental para a indústria, pois o aguilhão da fome tangeria-os para o trabalho. Quanto aos homens superiores, os capitalistas, estes eram motivados pela ambição. Movido por essas forças inerentes aos indivíduos, o mercado não necessitaria de nenhuma intervenção governamental. O livre jogo das forças agindo nos indivíduos, ainda que aparentemente desordenado, produziria uma harmonia em sua totalidade.

Na verdade, como certos defensores do mercado costumam admitir, o liberalismo radical seria um anarquismo Entretanto, os liberais não estariam dispostos a admitir outros valores do anarquismo sem cair em contradição. Contudo, certas linhagens liberais admitiram um intervencionismo mitigado ou até mesmo aprofundado. Isso se tornou uma tendência depois do Crack da bolsa de New York e da onda de falências, cortes drásticos na produção e nos investimentos, com altíssimo nível de desemprego. Como notam Hunt e Sherman (1977), enquanto durou o círculo vicioso do declínio da renda naci- 
onal e do desemprego em massa, milhares de corporações faliram e milhões de trabalhadores perderam seus empregos. Perante tal quadro ameaçador, da liberdade e da propriedade bens sagrados do credo liberal, surgem à idéia de um controle centralizado da economia, capaz de sanar os males provocados pelos desarranjos ou desajustes do mercado, que, na verdade, seriam crises profundas do capitalismo.

É em tal contexto, somado a ameaça comunista, que surge a doutrina econômica keynesiana. Conforme mostram Hunt e Sherman (1977, p.166-167), Keynes formulou sua doutrina a partir da constatação do não automatismo dos processos econômicos. O mesmo quadro utilizado para uma empresa isolada aplicar-se-ia também para a economia em seu conjunto. Os fluxos circulares apresentam vazamentos. Parte do dinheiro que flui das empresas para o público não retornaria diretamente para as empresas. Parte de semelhante renda seria poupada em Bancos. Embora esse vazio pudesse ser preenchido por aqueles que contraíssem empréstimos bancários e despendessem quantias superiores às suas rendas, Keynes teria constatado que, no auge da prosperidade a poupança geralmente supera os empréstimos aos consumidores, formando-se uma poupança líquida ou um vazamento real no fluxo circular rendas - despesas. Como outras fontes de vazamentos, Keynes teria indicado o fato de que ao adquirirem bens e serviços de empresas estrangeiras, as pessoas gastariam em importação o dinheiro que seria gasto com bens nacionais e ainda o fato de que as somas que as pessoas destinam ao pagamento do imposto são também retiradas do fluxo rendas - despesas. 0 não automatismo tenderia a gerar sempre desequilíbrios:

....quando se esgotam as oportunidades de investimento, os investimentos caem abaixo da poupança, e os gastos totais em bens e serviços caem abaixo do valor do conjunto de bens e serviços produzidos. As empresas não conseguem vender tudo o que produzem. Crescem os estoques de bens encalhados. Cada empresa enxerga apenas o seu problema, e como produz mais do que pode vender, no período subsequente ela reduz a produção. Acontece que o problema é extensivo a toda a economia, e como a maior parte das empresas toma a mesma decisão, ocorre, no período subsequente, uma violenta retração da produção, com aumento do número de desempregados e declínio da renda. Em conseqüência do declínio da renda, os gastos em bens e serviços serão ainda menores. Os empresários descobrem que, mesmo a níveis inferiores de produção, o círculo vicioso reproduz-se.

Conforme Keynes, as economias capitalistas maduras possuiriam um limite de oportunidades para investimentos lucrativos. $O$ mal vincular-se-ia ao fato de que "cada empresa enxergaria apenas o seu problema". O que para Marx e Lenin seria um mal incurável inerente ao capitalismo foi visto como 
susceptível de controle por intervenções destinadas a suprimir as distorções na distribuição de rendas e, conseqüentemente, reduzir a poupança de acordo com a proposta de Hobson (1977). Já para Keynes, quando a poupança excedesse os investimentos, o governo deveria intervir, recolhendo o excesso de poupança mediante empréstimo e investindo o dinheiro em projetos de utilidade social, visando criar condições para o pleno emprego, sem alterar 0 estoque de capital. Tratar-se-iam sobretudo de projetos ou investimentos em setores de utilidade pública, como a construção de escolas, hospitais, parques, etc.

O grande papel ideológico desempenhado pelas teorias de Keynes, segundo Saviani (1991, p.. 98) foi o de "atribuir importância central ao Estado no planejamento racional das atividades econômicas". Tornou-se um trunfo da burguesia que enfrentava ameaças advindas da crise interna do capitalismo e das "advertências" externas representadas pelo avanço da social democracia, vinculada aos movimentos socialistas e ainda dos feitos do comunismo na Rússia que, então tendia a se espalhar pelo mundo. Para Keynes, segundo Saviani (1991, p. 98),

a questão principal, era combinar a regulação da economia pelo Estado com o funcionamento da economia de mercado baseada na propriedade privada, numa tentativa de reestruturar o capitalismo a fim de evitar sua destruição devido às suas próprias forças. Daí, então, as propostas de intervenção govemamentais para conter as crises reincidentes, visando manter o pleno emprego e taxas de crescimento contínuas. Rompendo com os preceitos tradicionais do capitalismo admitiu-se como inevitável à intervenção governamental, com incrementos dos gastos públicos para incentivar a produção e o consumo, admitindo até mesmo os indigestos déficits orçamentários por parte do poder público.

Um outro fator político e ideológico importante analisado por Hunt e Sherman (1977, p. 177), refere-se ao fato de que as teorias keynesianas, principalmente com os reajustes de Samuelson, teriam proporcionado elementos para que a ideologia neoclássica enfrentasse o mais importante problema econômico da década de 30, mas ao mesmo tempo em que obscureceram ou agravaram outros problemas, como a concentração de poder econômico na mão de uma ínfima minoria. As tentativas de mostrar harmonias entre os grandes gigantes que se neutralizam ou a idéia de uma difusão da propriedade, pela rápida multiplicação do número de capitalistas, proporcionada pelo aumento do número de acionistas nada mais foram que novas formas de justificação do sistema capitalista, que em nada contribuíram para desfazer o seu caráter de iniquidade. 
A onda de intervencionismo gerou uma traumática crítica de um dos mais destacados defensores contemporâneos do liberalismo Friedrich A . Hayek, Prêmio Nobel de Economia, em 1974. Trata-se da obra O caminho da servidão (The Road to Serfdom), publicada pela primeira vez em 1944. Com ele, nasceriam os novos defensores da ideologia capitalista que, recentemente, se agruparam em torno do ideário neo-liberal.

Mesmo com toda a polêmica em torno do planejamento e da regulamentação da economia, tem vencido entre os liberais, a idéia de que a função do Estado é fortalecer e tornar mais eficaz o jogo da competição , que na verdade é um recrudescimento ou uma revitalização da ideologia capitalista clássica.

Atualmente, o capitalismo tem sua expressão ideológica, maior no denominado neoliberalismo. Essa nova versão da ideologia capitalista, radicaliza na proposta de redução das funções do Estado. O Estado mínimo deveria reduzir ao máximo o seu papel em relação à economia. Propõe-se um total desmantelamento dos sistemas públicos voltados para atender os setores sociais: como subsídios, investimentos diretos e regulamentação das atividades econômicas. Prega-se mesmo a desmontagem do sistema público de previdência social e a privatização das empresas estatais. A antiga noção de investimento público em setores estratégicos não faz mais sentido. No que respeita ao comércio internacional, as nações mais poderosas pregam uma total liberação de fronteiras e tarifas, se bem que, na verdade, eles continuam mantendo uma série de medidas protecionistas, que não se limitam às restrições do dumping social, mas a uma série de cobranças de taxas diretas e indiretas que acabam incidindo sobre os interesses dos parceiros comerciais, principalmente os mais fracos. Em seus artigos na Folha de São Paulo, Nassif tem sempre denunciado essas práticas escusas. Em termos práticos, os governos que mais se identificaram com as práticas neoliberais foram os de Margaret Tatcher, na Inglaterra, e Ronald Reagan, nos Estados Unidos.

De um modo geral, a visão liberal, em todas as suas fases, tem sido caracterizada pela preocupação com as condições de possibilidades de manutenção e atualização da força de produção. Como enuncia Saviani (1991), partir do advento das novas relações de produção capitalista, a escola tornouse o principal centro de educação:

inversamente ao que ocorria na sociedade feudal, é a troca que determina 0 consumo. Em conseqüência, o eixo do processo produtivo deslocou-se do campo para a cidade, da agricultura para a indústria, a qual converteu o saber, de potência espiritual (intelectual) em potência material, isto é transformou o saber (a ciência) em meio de produção. Assim, a estrutura da sociedade deixa de se fundar em laços naturais para se basear em laços propriamente 
sociais, isto é, produzidos pelos próprios homens. Daí, a sociedade contratual baseada no direito positivo e não mais no direito natural ou consuetudinário (...), assim, a sociedade moderna não podia mais se satisfazer com uma educação difusa, assistemática e espontânea, passando a requerer uma educação organizada de forma sistemática e deliberada, isto é , institucionalizada, cuja expressão objetiva já se encontrava em desenvolvimento a partir das formações econômico-sociais anteriores, através da instituição escolar. A escola foi, pois, enigida na forma principal e dominante de educação.(...) Em suma, por razões econômicas, sociais, políticas e ideológicas, a tese básica do liberalismo em matéria de ensino afirma o primado da instrução pública e, em conseqüência, o dever indeclinável do estado de organizar, manter e mesmo de impor a educação a toda a população.

A educação, ainda que muitas vezes tivesse seu caráter de investimento lucrativo negado, tornou-se sempre um fator de destaque nas preocupações empresarias. Desde as preocupações de Smith com uma instrução mitigada aos trabalhadores passando pela proposta de uma educação, mais diversificada e constante de Condorcet, chegando aos princípios da educação liberal contemporânea de adequação da mão-de-obra a partir da especialização e da disciplina, inerentes à proposta taylorista, tem se destacado o papel do Estado como responsável pela educação básica, ainda que devesse prevalecer a escola da livre iniciativa com objetos idênticos, isto é, voltados para a preparação do trabalhador com o objetivo de aumentar a sua eficiência e adaptabilidade, obediência aos imperativos da produção, ainda que as escolas particulares estivessem voltadas para o outro lado, o dos futuros dirigentes das linhas de produção. Sem falar das iniciativas das organizações empresarias para criar centros de formações específicas, de nível "básico" e "médio", como o SENAI e outros. Destacam-se, também, atualmente, as propostas pedagógicas - industriais no sentido de formar o trabalhador nas próprias fábricas. Na verdade, a luta de classes nas fábricas deve ser analisada em torno da relação teoria e prática, dos detentores do saber analítico - engenheiros - e funcional - discurso técnico e operativo.

A nova onda ideológica denominada neoliberalismo, concebendo-se como uma espécie de vitoriosa no campo histórico, político e até mesmo cientifico, ou pelo menos para explicar a função desse saber na sociedade, revela-se cada vez mais em conformidade com as novas descobertas científicas. Assim, os ideólogos recentes do capitalismo opõem a noção de rede ao conceito de lutas de classes. Em torno de tal conceito passa-se a explicar e justificar as atuais relações sociais, de modo a conciliar a dominação e exploração do capital sobre o trabalho. Ele permite também conceber um fim da história, na mediada em que se coaduna com os princípios pós-modernos, tais como desordem, caos, catástrofes, etc. O conceito de rede de certo modo 
é correlato à idéia de jogo. Se tudo é jogo, tudo vale, desde que se preserve o sagrado direito de propriedade, protegendo-o dos ataques dos perdedores recalcitrantes e de todos os demais ressentidos com o livre empreendimento.

Do ponto de vista político institucional, na lógica do pensamento liberal, a liberdade deve se coadunar com o sagrado direito da propriedade, a igualdade não seria pensada a não ser enquanto condições jurídicas e formais. Nesse caso, cabe ao Estado garantir as condições da igualdade formal e da liberdade de fato, ou seja, dos que têm poder e capital. A liberdade da mãode-obra deve ser a da alocação sem entraves. Cabe à formação da mão-deobra polivalente prepará-la para circular nas malhas da rede do capitalismo mundial. Os trabalhadores que não adquirirem um padrão que os possibilite tal flexibilidade formariam setores estagnados da rede em que as energias e saberes não circulariam, gerando nódulos de improdutividade. Por outro lado, o próprio capitalista estaria diluído numa rede de acionistas e em um centro de fluxos de ações, isto é, seria um grande apostador no cassino mundial, em que saber jogar é mais importante do que saber produzir com qualidade e competência. Os "trabalhadores" devem não só diluir-se nas equipes de produção, mas também, sobretudo estar capacitados para formar novos vínculos, para se deslocar dentro do fluxo que percorre as malhas da grande rede. 0 trabalhador, como o empresário, deve estar preparado para lidar com o imprevisível. Resta ver quais seriam as vantagens do trabalhador e como ficarão aqueles que não estivem inseridos na rede. O número destes tende a crescer, o que exigirá do sistema novos ajustes, que só a história dirá quais serão.

A noção de rede tem servido para se pensar uma forma de agregação em que os vínculos são locais, isto é, seriam tecidos a partir da formação de nós cuja consistência depende de elementos e forças contíguos que, embora sendo locais, encontrar-se-iam presentes por todo sistema reticular. A idéia de que as conexões locais, de certo modo, supõem desnecessário o papel de um tecelão centralizado, cuja atividade determinaria os vínculos. Daí também a idéia de que o crescimento da rede não obedeceria a nenhum programa traçado de antemão, podendo se estender nos mais variados sentidos. A interligação da rede colocaria em comunicação todos as suas partes, de modo que um acontecimento num local poderia afetar todas as partes conexas ao sistema.

Pensado enquanto tal, o ideário de rede seria mais conceptível dentro dos supostos anarquistas de autogestão. Os "liberais", de um modo ou de outro, sempre necessitarão de um poder central de agregação capaz de manter a ferro e fogo certas tendências conforme os interesses do capital. Uma democracia radical, isto é, em que as bases determinariam os rumos a serem dados à vida pública, seria totalmente imprevisível, podendo caminhar 
tanto no sentido de estabelecer a tirania, portanto de negar a si mesma, como também de evoluir num sentido comunista, ambos contrários ao consenso liberal. Nesse sentido, o Estado liberal será sempre um poder em prontidão, ainda que recue ao máximo possível. Caberá a ele manter o consenso ou a hegemonia burguesa, não importando qual o meio. Como vimos, para alcançar tal objetivo, vale lançar mão até do "planejamento", como afirma Keynes, quando este for conveniente. Não propomos estudar aqui as implicações da noção de rede no ideário anarquista. Mas apenas indicar a sua inviabilidade para se pensar o o sistema liberal. Neste, "os nós" são afrouxados ou tencionados conforme intenções e pressões de uma "mão invisível", às vezes, embora quase sempre bem visível. - O "Grande Irmão" e o Leviatã - ainda que imperceptíveis não descansam na contínua tarefa de manter a harmonia entre os desiguais. Aqui nós vemos que o ideal burguês da liberdade de empreendimento e harmonia entre interesses egoístas particulares e o bem público, além de supor a desigualdade como natural, e constituindo mesmo o motor da economia, admitiriam um Estado de prontidão, capaz de manter as coisas determinadas pelo mercado. Os reclames de Rousseau e outros contra os males da liberdade da articulação dos interesses privados que deixados por si só não poderiam produzir o bem comum, tem sentido, mas o ideário da harmonia do livre jogo de interesses revelou-se também incapaz de subsistir por si só, mesmo para manter a desigualdade. A sociedade liberal precisou sempre de um poder coercivo, ainda que não ostensivo.

Ainda que no ideário liberal a interferência central não seja necessariamente planejadora, uma vez que ela iria contra o credo da auto-regulação do mercado, ela não poderia deixar de ser conservadora de determinadas tendências, no caso, a concentração de renda. Enquanto essa tendência não estivesse ameaçada, o Estado manter-se-ia distante, contudo, ele tende a interferir nos mais diversos níveis - ideológico, força, econômico - para manter os rumos do mercado, e sua ação se faz sentir conforme as ameaças a estes.

A sociedade aberta tal como teria concebido Popper, bem como o estado mínimo dos neoliberais possui seus limites. Uma sociedade radicalmente aberta seria anarquista. A abertura implicaria sempre uma indefinição do momento seguinte, o que o sistema capitalista não admitiria jamais. Isso implica que o Estado mínimo liberal tem seus limites de encolhimento ou pelo menos de ostentação. Ainda que os neoliberais vejam toda forma de planejamento como uma ameaça à liberdade e um risco de conceber terrenos ao totalitarismo, eles não poderiam deixar de lançar mão de um Estado forte, ativo e coercitivo para manter a ordem liberal. A presença do Estado é indispensável ainda que no processo de globalização este venha sofrendo reestruturações.

A globalização tem se caracterizado por uma relativização do poder 
dos estados nacionais no tocante ao controle do processo de produção e distribuição da riqueza. Este processo tem adquirido cada vez mais dimensões mundiais. A globalização significa, sobretudo um surto de universalização do capitalismo, como modo de produção e processo civilizatório. Trata-se de um desenvolvimento "intensivo e extensivo" do capitalismo devido à recente revolução tecnológica ligada à informatização de processos produtivos e com a reviravolta nos meios de informação. Com isso, verifica-se o advento de novos bens de consumo, a "recriação" da divisão internacional do trabalho e a "mundialização" dos mercados. O capitalismo globalizou-se também pela sua "penetração" na parte do mundo que até em 1989, antes da queda do muro de Berlim e a desagregação econômica, territorial, geográfica, cultural da antiga União Soviética e das nações a ela ligadas, era de economia socialista, planejada e centralizada. Contudo, o capitalismo global está intimamente ligado com o capitalismo nacional. Nesse sentido, o capitalismo competitivo, monopolístico e de estado não está superado pelo capitalismo global.

A globalização marca-se por uma reviravolta comercial, tecnológica e organizacional, em que as estruturas decisórias transcendem as fronteiras geográficas e decisionais das nações. A força do mercado tende a ser controlada por estruturas transnacionais, tais como as corporações e multi e transnacionais, bem como os órgãos multilaterais ligados aos interesses das mesmas e das nações em que mantêm suas bases de ação. Entre esses órgãos multilaterais, destacam-se a Organização das Nações Unidas (ONU) o Fundo Monetário Internacional (FM), o Banco Mundial, Organização Mundial do Comércio (OMC) , Banco Internacional de Reconstrução e Desenvolvimento (BIRD), Organização Internacional do Trabalho (OIT), o G-7 ( EUA, Japão, Alemanha, França, Inglaterra, Itália e Canadá) e o G-3 (EUA, Japão e Alemanha), bem como os blocos regionais.

Tratam-se de tecnoestruturas ampliadas de controles e decisões que envolvem o local, o regional e mundial. Visam, sobretudo, "dinamizar e modificar o foco das forças sociais, em conformidade com os interesses prevalecentes nas estruturas de dominação política e apropriação econômica". Parece que, segundo IANNI (1996, p. 122) a própria soberania nacional tende a se reduzir, de modo que o Estado-Nação começa a ser obrigado a compartilhar ou aceitar decisões e diretrizes provenientes de centros de poder regionais e mundiais. Entretanto, admite também IANNI (1996), por mais errático que o capital tem-se tornado com a globalização, ele mantém bases de ação que garantam sua segurança, o que confere as nações centrais do capitalismo um papel hegemônico. A idéia de um mercado enquanto uma grande rede tecendo a si mesma, sem centro nem hierarquia de comandos centralizados, em conformidade ainda com a metáfora da mão invisível, não pode ser admitida sem parcialidade, 
Jogando com as convergências e os antagonismos entre nacionalismo, regionalismo e globalismo, encontram-se as empresas, corporações e conglomerados transnacionais. Tecem a globalização desde cima, em conformidade com a dinâmica dos interesses que expressam ou simbolizam. Desenham as mais diversas cartografias do mundo, planejadas segundo as suas políticas de produção e comencialização, preservação e conquista de mercados, indução de decisões govemamentais em âmbito nacional, regional e mundial (IANNI, 1996, p. 119).

Daí, então, poder-se falar de um novo intelectual orgânico que se incorpora na mídia e nos intelectuais a serviço do sistema capitalista. A mídia atuando das e para as mais diversas localidades sempre no sentido de manter um consenso em torno dos valores da globalização. Os intelectuais especialistas em tomadas de decisão, os que "planejam" as ações das corporações, traçam estratégias de mercados, indicando as possibilidades de aumentar a competitividade, etc. O globalismo, a mundialização compreende uma abertura histórico-geográfico de um campo de disputas entre capital trabalho, entre empresas em competição, entre estados em disputas por investimentos e controles estratégicos das corporações, entre o local, o regional e global.

A nova divisão internacional do trabalho redistribui, por todos os países e continentes, empresas, corporações e conglomerados, agências publicitárias e mídia. Essa nova redistribuição determina novas formas de organização social da produção. O fordismo passa a "combinar-se com ou ser substituído pela flexibilização dos processos de trabalho e produção". Juntamente com os novos produtos e padrões de consumo surgem novos setores de produção e novas formas de serviços financeiros, novos mercados. Vale agora, ao lado da produtividade, a capacidade de inovação e competitividade. As novas formas de organização social e técnica do trabalho forma um "trabalhador coletivo desterritorializado". O mundo transforma-se "em uma imensa fábrica", a "fábrica global". Exige-se agora um trabalhador polivalente. A força de trabalho é cada vez mais tecnificada. Ao lado das múltiplas possibilidades de mobilidade social (vertical, horizontal) ocorre um ajuste dos trabalhadores às novas exigências da produção de mercadoria e excedente, lucro ou mais valia. Estamos perante um novo modelo de racionalização da produtividade ampliada do capital, dando-se em escala global.

A sociedade global apresenta-se como uma totalidade "complexa, contraditória e aberta". Ela subsume localidades, nacionalidades, nações e religiões, "compreendendo ilhas, arquipélagos e continentes, mares e oceanos; constituindo territorialidades e temporalidade desconhecidas". Contudo, no que se refere aos estados nacionais, eles tendem a se constituírem em patamares de articulações de interesses dos povos. Caso contrário, os governantes submeterão suas nações às forças do mercado mundial que não respeitam 
interesses nacionais, culturas, identidades, e muitos menos preocupam-se com a exclusão de indivíduos e grupos do acesso ao trabalho, aos bens de consumo, a cultura e à cidadania ou direito de autodeterminação. Nesse sentido, cabe ao estado-nação definir interesses conforme uma população, um território, uma cultura, uma tradição, mantendo uma abertura para o estrangeiro e uma identidade nacional. Na medida em que prevalece em um país os interesses das foças globalizadas, sua soberania tende a ser reduzida. $\mathrm{O}$ grande desafio é o de manter uma abertura e preservar a soberania, uma vez que 0 intercâmbio de bens, serviços tecnologia e informação são imprescindíveis. É imprescindível para que as sociedades nacionais possam se redefinir frente ao movimento de mundialização do capital. Mas esse movimento em sua natureza em nada difere do movimento das nações, a não ser em sua escala e poder de subsunção ampliado. Ambos "formam-se e se conformam, afirmam-se e se transformam, integram-se e se rompem". O que é valido para a nação, vale para o mundo.

A nação é uma criação simultaneamente geográfica, econômica, demográfica, cultural, social e política, com todas as características de um processo histórico. Forma-se e transforma-se segundo o jogo das forças sociais internas e externas, modificando-se de tempos em tempos, ou continuamente. As nações transformam-se em espaços, territórios ou elos da sociedade global. Esta é a nova totalidade em movimento, problemática e contraditória”.Trata-se de "um processo em constante devir, direcionado e errático, in tegrativo e fragmentário". (NASSIF, L O protecionismo americano. Folha de são Paulo, 14 nov. 1997).

\section{Notas}

"Todos questionam a crença de que os interesses privados possam confluir para gerar um ordenamento social igualitário e harmônico e lhe opõem um modelo em que indivíduos e grupos se articulam, por sua própria vontade, visando ao interesse geral. Opondo-se não apenas ao arbítrio do Rei e da Igreja, mas, também aos males do capitalismo nascente, denunciam o aspecto destruidor do comércio e da riqueza e põem sob suspeita a certeza, difusa entre a intelligentsia do século das luzes, de que a conveniência pacífica dos homens possa fundar-se sobre a organização racional dos interesses particulares". PIOZZI, P., Natureza e artefacto: a ordem anárquica., Tese de Doutorado, São Paulo, USP, 1991, p. 4.

O liberalismo jamais poderia conceder a cada homem "o direito, se o desejar, de modelar ele próprio a sua vida, enquanto isso não interferir na vida dos outros". Ver POPPER, K. A sociedade aberta e seus inimigos, Liv. Itatiaia, p. 181. Além do mais, para os neo-liberais 0 sistema não comportaria não uma "mecânica utópica" , em que tudo seria modelado conforme um ideal dado de antemão, nem mesmo uma mecânica gradual, em que os ajustes seriam acrescidos conforme as possibilidades inerentes a um conhecimento sempre parcial, uma vez que o "conhecimento necessário à mecânica em ampla escala simplesmente não existe." FRIEDMAN, M. afirma que, "tanto nosjogos como nas sociedadesnenhum conjunto de regras 
pode prevalecer, a não ser que a maioria dos participantes as obedeça durante a maior parte do tempo, sem a necessidade de sanções externas, a não ser, portanto, que exista um consenso social subjacente. Mas, não podemoscontar com o costumeou com esteconsen so somentepara interpretar e por regras em vigor; é necessário um árbitro. Estes são, pois, os pa péis básicos do governo numa sociedadelivre- prover osmeiospara osmeiospara modificar asregras, regular as diferenças sobre seu significado, e garantir o cumprimento das regras por aqueles que, de outra forma, não se submeteriam a elas". In Capitalismo eliberdade, ed. Artenova S\A, 1977. p. 32.

\section{Referências}

HUNT; SHERMAN. História do pensamento econômico. Rio de Janeiro, RJ: Vozes. 1977. p.56

HUNT; SHERMAN. História do pensamento econômico. Rio de Janeiro,RJ: Vozes. 1977. p.58-59

SAVIANI, D. Educação e questões da atualidade. São Paulo,SP: Cortez, 1991. p. 98.

IANNI, O, Teorias da globalização, Rio de Janeiro: Civ. Brasileira, 1996. p. 122; 149.

. Nação e globalização. In: . A era do globalismo. Rio de Janeiro,RJ: Civilização brasileira. 1996. p. 100. p. 110 .

A era do globalismo. Rio de Janeiro,RJ: Civilização brasileira. 1996.

Recebido em 30/10/03

Aprovado em 28/11/03 